\title{
El cuaderno de campo como eje del aprendizaje de naturaleza cercana en Educación Infantil
}

\author{
Sara Pinillas Fernández \\ Departamento de Ciencias de la Educación, Universidad de Oviedo.España.sarapinillas@gmail.com \\ Antonio Torralba-Burrial iD \\ Departamento de Ciencias de la Educación, Universidad de Oviedo. \\ Instituto de Recursos Naturales y Ordenación del Territorio, Indurot. Universidad de Oviedo. España. \\ torralbaantonio@uniovi.es
}

[Recibido: 8 enero 2021. Revisado: 27 febrero 2021. Aceptado: 30 abril 2021]

\begin{abstract}
Resumen: Existe una desconexión creciente de la sociedad con la naturaleza, que comienza en la infancia y en mayor medida en las ciudades. La educación, desde la primera infancia, debe representar una vía muy importante en su reversión, para lo que resulta importante disponer de experiencias contrastadas, menos frecuentes en las edades tempranas. Se presenta una experiencia didáctica de conocimiento de la naturaleza cercana en segundo ciclo de Educación Infantil, basada en la búsqueda, observación, y clasificación de los seres vivos del patio escolar vegetado, la experimentación con elementos naturales en el patio, y en la que se emplea como eje del aprendizaje el registro de dichas observaciones (fundamentalmente gráfico, pero que incluye también palabras y fechas) en un cuaderno de campo individual de cada estudiante y otro colaborativo del conjunto del alumnado, que ha facilitado el aprendizaje científico del medio natural.
\end{abstract}

Palabras clave: didáctica del medio natural; educación infantil; educación ambiental, educación científica, patio escolar.

The field notebook as close nature learning axis in Early Childhood Education

Abstract: There is a growing nature disconnection in society, which begins in childhood, more preocupant in cities. Education, starting in early childhood, should play a important role in reverse this disconection, using teaching-learning experiences and resources useful and tested, what less frequent in early ages. A didactic experience to increase close nature knowledge in the second cycle of Early Childhood Education is showed here. This experience is based on the search, observation, and classification of living beings in the vegetated schoolyard and scientific experimentation with natural elements, using as a learning axis field notebooks, an individual notebook filled by each student and a collaborative one by the full group. In the fieldnotes the students recorded observations mainly combining drawings, some words and dates, enhance scientific learning of the natural environment.

Keywords: natural environment teaching; early child education; environmental education; science education; schoolyard.

Para citar este artículo: Pinillas Fernández S. y Torralba-Burrial A. (2021) El cuaderno de campo como eje del aprendizaje de naturaleza cercana en Educación Infantil. Revista Eureka sobre Enseñanza y Divulgación de las Ciencias 18(3), 3202. doi: 10.25267/Rev_Eureka_ensen_divulg_cienc.2021.v18.i3.3202

\section{Introducción}

Existe una desconexión cada vez mayor entre la sociedad y el conocimiento de la naturaleza, que se inicia durante la infancia (Ballouard et al. 2011; Genovart et al. 2013) y se continúa y amplía en la población adulta (Pyle 2003). No obstante, a la hora de valorar como se afronta la situación en la Educación Infantil, encontramos que apenas la tercera parte del profesorado asocia el aprendizaje de la biodiversidad con la de su entorno más próximo en centros escolares asturianos, y solo un 7\% afirma realizar salidas didácticas específicas para su aprendizaje (Segura y Torralba-Burrial 2019).

Para reajustar el sistema y acercarnos a la senda de la sostenibilidad debe desempeñar un papel fundamental la educación (Vilches et al. 2009). De hecho, se ha propuesto como una de las 
medidas clave el incremento en la educación sobre la naturaleza en la infancia, lo que generaría mayor concienciación en el conjunto de la sociedad (Ripple et al. 2017). Estos procesos de enseñanza-aprendizaje del medio natural deberían incorporar necesariamente las experiencias en el medio natural (Bögeholz 2006), experiencias marcadas por un carácter científico (Mérida Serrano et al. 2017), con planteamientos de Educación Ambiental (Cutter-Mackenzie et al. 2014) y que incluyeran la realización de experimentos (Braund y Reiss 2004; Loxley 2018).

Pero a la hora de llevarlo a cabo, resultan relativamente escasas las experiencias de educación ambiental y conocimiento del entorno publicadas en Educación Infantil desde un planteamiento de enseñanza de las ciencias (véase Cantó Doménech, de Pro Bueno y Solbes 2016; Varela-Losada et al. 2016). En este contexto, el diseño de experiencias didácticas en las que se aborde el conocimiento científico de la naturaleza en la Educación Infantil, resulta de sumo interés, tanto por su valor de incremento del conocimiento directo de la didáctica de las ciencias en esta etapa como por su valor replicativo (Cruz-Guzmán, García-Carmona y Criado 2017; de Alba Villaseñor y Ramos de Robles 2020; Gómez-Motilla y Ruiz-Gallardo 2016; Monteira y Jiménez Aleixandre 2019).

Aquí presentamos una experiencia didáctica de conocimiento de la naturaleza cercana en segundo ciclo de Educación Infantil basada en la observación, búsqueda y clasificación de los seres vivos del patio escolar vegetado, la experimentación con elementos naturales, y el registro de dichas observaciones en un cuaderno de campo individual y otro colaborativo del alumnado.

\section{El patio escolar en el aprendizaje de las ciencias}

Desde una perspectiva ya histórica, Rosa Sensat otorgaba especial importancia al desarrollo de actividades en el medio natural como fórmula necesaria para el desarrollo del infante: «La naturaleza es el ambiente más adecuado a la normal evolución del niño, asegurando el derecho que éste tiene al aire puro, a la luz del sol, al agua, al ejercicio físico y a la libertad y alegría» (Sensat Vilá 1921). Así pues, proponía indicaciones para que los maestros y maestras favorecieran el contacto, la observación y experimentación del entorno natural independientemente de si se tratasen de escuelas de zonas rurales o urbanas, proponiendo para estas últimas, además de salidas al campo, recorridos por las zonas verdes urbanas, parques o incluso jardines (Jiménez Artacho, Fernández Pérez y Fonfría Díaz 2004). Similares planteamientos para la enseñanza de las ciencias naturales en la naturaleza planteaban Enrique Rioja, Margarita Comas o Vicente Valls en sus escritos clásicos en este campo (López Martínez y Delgado Martínez 2014). Y es que, para aprender sobre el medio natural, la fauna y la flora, no es necesario realizar expediciones (reales o virtuales) a selvas remotas ni a puntos calientes de biodiversidad, sino que podemos explorar con nuestro alumnado con mucha más facilidad la biodiversidad urbana (Abelleira Bardanca 2016; Torres-Porras et al. 2017).

En este sentido, un patio escolar provisto de zonas con vegetación puede ser una infraestructura muy adecuada para el aprendizaje de la naturaleza cercana (Conde Campos y Pinzolas Torremocha 2006), en el que podemos implementar incluso algunas de las actividades en boga en las escuelas bosque (Equipo de Educación Infantil del C.P. Marcos del Torniello 2020; García-González y Schenetti 2019), y que presenta la ventaja de estar disponible en algo más de la mitad de los centros en los que se imparte alguno de los ciclos de Educación Infantil en Asturias (Segura y Torralba-Burrial 2019). En el caso de que no estuviera disponible, en todos los patios escolares podríamos realizar actividades de observación del medio en mayor o menor medida (Marín et al. 2010). Así, Louv (2018) expone que deberíamos considerar los entornos naturales cercanos a las escuelas como aulas, mientras que Heinecke (2016) propone su utilización como laboratorio para la enseñanza de las ciencias en la infancia, coherente con el estudio científico de su biodiversidad (Kneidel 1993). Además, el traspasar procesos de enseñanza-aprendizaje del aula al patio escolar puede ser una importante ayuda en periodos en los que se requiere un mayor espacio para cada estudiante, como los ocasionados por la pandemia derivada de la COVID-19. 


\section{Organización de las observaciones desde el cuaderno de campo}

El cuaderno de campo es una de las herramientas más útiles y necesarias para recoger observaciones científicas sobre el medio natural. Una breve descripción de su utilización y cómo abordarlo puede encontrarse en la mayoría de los manuales de introducción a la observación del medio natural en la infancia. No obstante, pueden tener estructura, estilo y amplitud diferente en cada nota, las cuales varían también mucho dependiendo de persona que observa (ver amplitud e importancia presente e histórica en Canfield 2011), pero siempre implican una primera reflexión sobre lo observado a la hora de tomar las notas o realizar los dibujos pertinentes. Proporcionan por tanto un contexto a los datos, combinando datos estructurados y no estructurados, que constituyen una narrativa concreta y personal de dichas observaciones (Thomer et al. 2012). En ocasiones, se complementa igualmente con las observaciones relacionadas derivadas del laboratorio, y en otras forman herramientas distintas. Clásicamente desarrollados en cuadernos de papel, en la actualidad existen alternativas digitales, adaptadas a dispositivos móviles, que bien guardan la información localmente o bien la guardan o incluso comparten (privada o públicamente) por Internet.

Los cuadernos de campo realizados por el alumnado han dado muy buenos resultados en el aprendizaje del medio natural y la evaluación de dicho aprendizaje, especialmente en estudiantes de educación superior (Hayes 2009; Wolff y Skarstein 2020), secundaria (Brody 2005) y últimos cursos de primaria (Scott y Boyd 2016). No obstante, su implementación en la educación infantil y primeros cursos de primaria parece más limitada por situarse al comienzo de los procesos de lectoescritura. En estos casos, una forma de comprender lo que han aprendido de medio natural se puede implementar a través de la realización de dibujos que integren esas actividades de aprendizaje (Dai 2017; Snaddon, Turner y Foster 2008; Torralba-Burrial 2019; Villarroel, Antón, Zuazagoitia y Nuño 2018). No obstante, en la actualidad gran parte del alumnado de Educación Infantil ya maneja de una forma inicial la lectoescritura al finalizar la etapa, y las fichas que integran palabras, números y dibujos son una de las metodologías más habituales en el segundo ciclo (Cantó Doménech, de Pro Bueno y Solbes 2016). Por lo tanto, pasar desde la realización de fichas temáticas a su organización en forma de cuaderno de campo supone una motivación extra para el ejercicio de lectoescritura y lógico-matemático, ya que pueden entender su realización como una necesidad real. En el cuaderno de campo resulta necesario anotar lo que se ha visto hoy para poder recordarlo, compararlo con otras observaciones y cotejarlo con el resto del alumnado.

\section{Metodología}

\section{Contexto}

La experiencia ha sido desarrollada durante el segundo y tercer trimestre del curso 2018/19 en el colegio CEIP Villafría de Otero, centro de línea 1 situado en un entorno periurbano de la ciudad de Oviedo. El alumnado proviene en su mayoría del barrio, con un 23\% proveniente de zona rural. En todo caso, un entorno con abundantes zonas verdes y mosaico de zonas naturales en la interfase urbano-rural.

Los edificios que conforman el centro educativo (Educación Infantil, Educación Primaria y Polideportivo), se encuentran rodeados de zonas vegetadas con variedad de especies. Bordeando el edificio principal se encuentra el huerto escolar, utilizado en algunos cursos de educación primaria y por la Asociación Síndrome de Down del Principado de Asturias. Además de varios espacios para el huerto, se contaba con dos compostadoras y una mesa de cultivo.

La clase en la que se implementó era de segundo curso del segundo ciclo de Educación Infantil (alumnado de 4-5 años), con 20 estudiantes (13 niños, 7 niñas). 


\section{Breve descripción de la experiencia didáctica}

La experiencia ha partido de un diagnóstico inicial, en el que se ha valorado tanto la utilización previa del patio escolar y su potencialidad para el conocimiento del medio natural como los conceptos previos e ideas alternativas que presentaba el alumnado. En este sentido, el patio escolar se constituye en el lugar donde realizar fundamentalmente la experiencia, entorno pedagógico adecuado para desarrollar los procesos de enseñanza-aprendizaje de la naturaleza cercana. Atendiendo a ese diagnóstico inicial, y con modificaciones de acuerdo a la evaluación procesual llevada a cabo durante la experiencia, se organizaron actividades destinadas a mejorar el conocimiento del alumnado sobre las plantas y los animales del entorno cercano, a partir de experiencias centradas en el patio escolar, y apoyadas con algunas actividades realizadas en el aula con materiales y recursos obtenidos de dicho patio. Estas actividades se pueden agrupar en las orientadas a descubrir las partes de las plantas, experimentar sobre su desarrollo, trabajar el medio natural mediante diversas experiencias en el huerto escolar, identificar los árboles del patio, descubrir y observar a los animales presentes y experimentar con los elementos naturales disponibles, todo ello siendo registrado a través de los cuadernos de campo individual y colectivo (Figura 1).

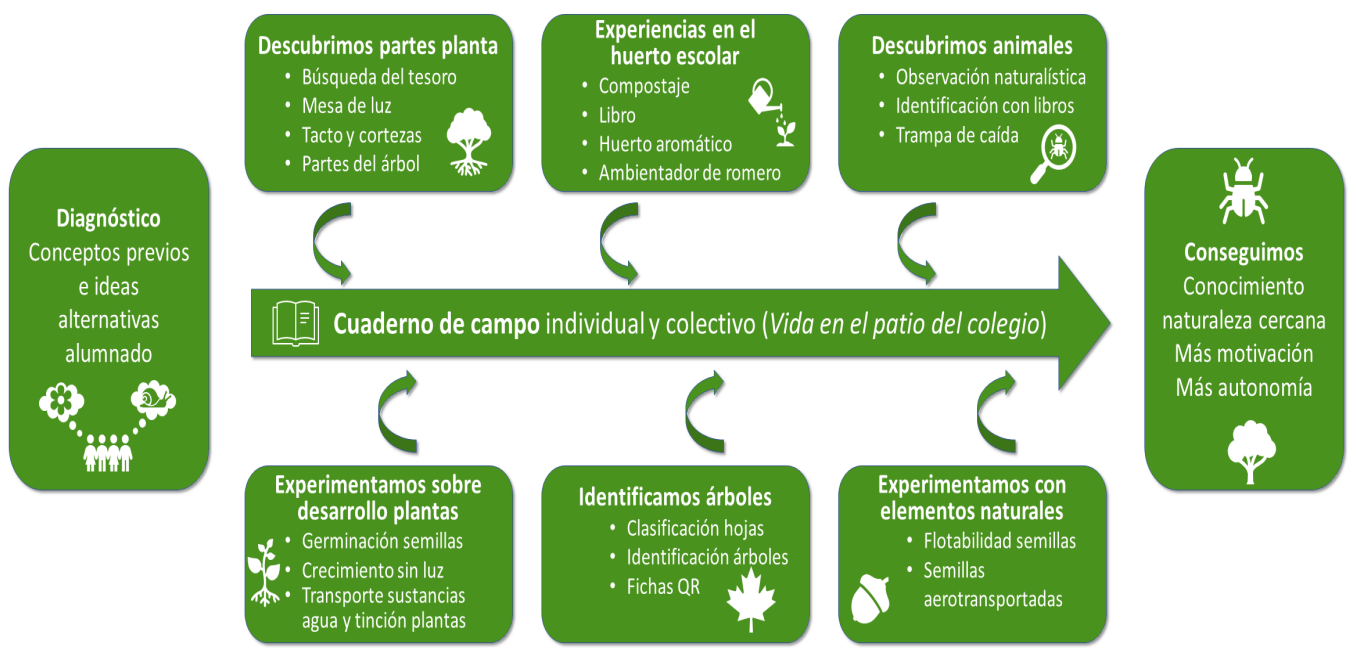

Figura 1. Diseño de la experiencia de aprendizaje de la naturaleza cercana en el patio escolar en segundo ciclo de Educación Infantil tomando como eje el cuaderno de campo individual y colectivo.

En este sentido, el cuaderno de campo individual constituye el registro y guía de las actividades realizadas, en el cual se incorporan algunas de las producciones realizadas por el alumnado, como, por ejemplo, dibujos de las observaciones realizadas, anotaciones sobre los experimentos llevados a cabo y esquemas sobre lo aprendido. Se ha configurado para ir recogiendo esta información en cuartillas (DIN A5) que se fueran realizando y uniendo mediante encuadernadores, facilitando su manejo por el alumnado. Con el fin de proporcionar una estética inicial identificativa, se creó una portada con la imagen genérica de un explorador/a sin rostro donde colocaron su fotografía, pegando el título de Cuaderno de campo.

La construcción de este cuaderno, anotando el alumnado palabras que tienen sentido en su experiencia, escribiendo con una finalidad, recordando datos o anécdotas, comparando situaciones experimentales... que acompañan a los dibujos, supone un ejercicio de lectoescritura con una motivación real (Erickson y Wharton-McDonald 2019).

A modo de un cuaderno colectivo de observaciones científicas sobre la naturaleza cercana, se ha creado un álbum de imágenes e información a medida que se han ido descubriendo los seres vivos que habitan en el patio del colegio. Este cuaderno colectivo se ha configurado como archivador con fundas plásticas en las que se introducían láminas creadas por el grupo. Las láminas mostraban (al menos) una imagen del animal o planta, junto con su nombre y 
alguna palabra clave, así como productos de actividades realizadas de forma grupal, y otros materiales que el conjunto de la clase considerara de interés. Denominado (tras propuestas y votación del alumnado) como Vida en el patio del colegio, ha acabado conteniendo 20 láminas de animales, 27 plantas y 13 producciones grupales. El cuaderno grupal se ha mantenido de forma permanente en el rincón de la naturaleza, accesible para el alumnado, que ha podido consultarlo de forma autónoma.

\section{Desarrollo de la experiencia y resultados}

\section{Situación inicial}

El análisis de la situación previa en la que se encontraba el patio escolar indica que su uso previo era fundamentalmente lúdico, durante el recreo, o para actividades de psicomotricidad y educación física. En el caso de las zonas vegetadas, no estaba permitido al alumnado su disfrute autónomo, como otro espacio más de juego, aunque sí que las utilizaban fuera del horario escolar con sus familias. No se le daba un uso relacionado con el conocimiento del medio natural, pese a tener en su interior zonas vegetadas con una relativa amplia diversidad vegetal (se identificaron al inicio de la experiencia 19 especies de árboles, 4 de arbustos y numerosas herbáceas). Pese a la existencia de un huerto escolar en el patio, solo era empleado en actividades docentes del colegio en Educación Primaria, mientras que para Educación Infantil se había empleado en el pasado una mesa de cultivo, si bien se encontraba en desuso previamente a esta experiencia. Ofrecer una posibilidad de cambio a esta situación, buscando un acercamiento a la naturaleza próxima en el propio patio escolar, determinó el diseño de base de las actividades que conforman esta experiencia.

Para recoger la situación previa del alumnado, se realizó una evaluación inicial mediante conversación durante la asamblea, planteando una serie de cuestiones destinadas a recoger sus ideas previas sobre la biodiversidad cercana, aquella que podían encontrar en el patio escolar y en sus experiencias en el entorno cercano, con las que poder diseñar más adecuadamente unas actividades que respondieran a sus necesidades específicas. Al preguntar por los seres vivos que podemos encontrar en el patio, el alumnado respondió con nombres de animales (hormigas, caracoles y moscas), sin incluir a las plantas. Insistiendo en este aspecto, sí que indicaron la presencia en el patio de margaritas y dientes de león. No conocían los nombres de ninguno de los árboles presentes en el patio escolar, recordando como nombres de árboles de su entorno el pino y el castaño. No habían interiorizado todavía las partes de un árbol, que categorizaban en madera y hojas, sin asociar sus funciones. Consideraban que el rasgo en el que más difieren unas hojas de otras es el tamaño, e identificaban como cambio en los árboles a lo largo de las estaciones la pérdida de las hojas (tras un pequeño debate en el grupo, se concluyó que no todos los árboles pierden las hojas). No indicaban otras manifestaciones fenológicas en los árboles, pero, al ser preguntados sobre motivos para cuidar árboles y plantas, o para qué consideran que sirven, sí que hicieron referencia a la fruta. De ahí se mueve el interés en la asamblea hacia las semillas como elemento de reproducción de las plantas, y su desarrollo, en el cual solo requieren agua (lo que resulta coherente con la falta de función identificada previamente para las hojas).

Las respuestas dadas en la asamblea, que mostraban tanto conocimientos como actitudes, fueron empleadas para crear cuatro equipos heterogéneos en cuanto a perfil sociológico y conocimientos previos, que se han mantenido en el trascurso de las actividades y salidas. Cada equipo eligió su nombre, y tres se nombraron en función de sus expectativas con la función de búsqueda y exploración a realizar (superinvestigadores, patrulla de los exploradores, piñadores), mientras que el cuarto recibió el nombre de un color $(a$ ą) $)$. 


\section{Aprendiendo sobre la diversidad de plantas}

Atendiendo a las ideas presentes en el alumnado, las actividades dirigidas al aprendizaje sobre plantas en el patio escolar se han orientado a descubrir las partes de las plantas, comprender cuestiones sobre su fenología, algunos usos de las plantas y a ser capaces de identificar algunas de las presentes en el patio.

La combinación de cuatro actividades complementarias para descubrir las partes de las plantas (búsqueda del tesoro, actividad sensorial con mesa de luz, actividad sensorial sobre las cortezas y mural sobre las partes del árbol) permitió al alumnado explorar las distintas partes, sus características visuales y táctiles, aprenderlas y diferenciarlas. La búsqueda del tesoro resultó sumamente motivadora y, de hecho, el alumnado recogió más elementos que los solicitados, que pudo emplear en la mesa de luz. En esta, por su parte, al eliminar el color como elemento descriptivo, empezaron a emplear conceptos como la forma de la hoja y de su borde, anteriormente ocultos para sus preferencias por el color. Esto resulta de especial interés, al ser características en las que posteriormente deberán fijarse en la identificación de los árboles.

Las especies de árboles presentes en el patio sobre las que se centró el aprendizaje fueron seleccionadas atendiendo a su importancia cultural o su abundancia en la zona, además de al interés manifestado por el alumnado. Se procuró que su identificación fuera realizada por el propio alumnado, mediante la comparación con las imágenes de varios libros. A ese respecto, la identificación que más recordaron fue la de la hoja del roble carbayo, por su forma lobulada característica, además de ser un árbol ampliamente distribuido en su entorno cercano y región, y estar asociado a la ciudad de Oviedo hasta el punto de que sus habitantes reciben el apodo de carbayones. Además, el árbol más cercano al aula era un roble.

Cuando un árbol no presentaba las partes en las que se fijaban para su identificación (p.e. en invierno hojas de especies caducifolias), debían realizar apuntes gráficos en su cuaderno de campo y ver los cambios posteriores (Figura 2, ejemplificado con los cambios fenológicos entre dos observaciones separadas un mes en el magnolio de hoja caduca).

En cuanto a la descripción de las hojas según morfología, la mayoría del alumnado describió correctamente como hoja en forma de palma (para el plátano de sombra) y de aguja (para el cedro), debido a que evocan la experiencia previa del alumnado, lo que les permite recordarlos con mayor facilidad y aplicarlos adecuadamente al describir las hojas.

Por lo que respecta a los arbustos, buena parte del alumnado identificó el romero, debido a que se trabajó en el huerto escolar más intensamente, en algunos casos al tocarlo y oler sus manos después.

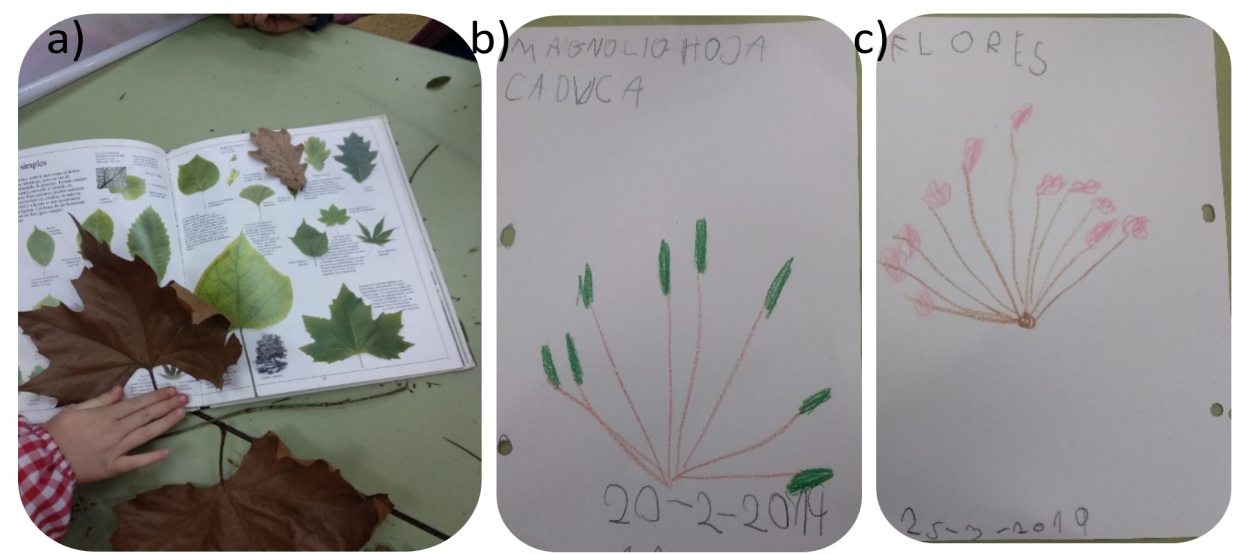

Figura 2. Identificación de árboles mediante caracteres que pueden cambiar con el paso del tiempo: a) identificación de hojas por comparación con fotografías en libros; b) apunte gráfico en el cuaderno de campo del magnolio de hoja caduca a finales de febrero, con las yemas de las futuras flores visibles; c) apunte gráfico del mismo magnolio un mes después, con las flores. 


\section{Aprendiendo sobre la diversidad de animales}

Las primeras actividades de observación de animales en el patio escolar se basaron en una observación naturalística dirigida a los animales, llevada a cabo cuando se salía a la zona vegetada del patio escolar. En algunos casos, los animales fueron recogidos, observados en el aula (con las debidas precauciones para evitarles daños), dibujados (Figura 3) y después liberados de nuevo en el patio escolar.

Estas actividades han permitido ampliar notablemente su conocimiento sobre la fauna cercana. Invertebrados como las lombrices o caracoles fueron detectados con facilidad, así como algún pequeño vertebrado (lagartijas roqueras y algunos pájaros), que fueron incorporados al cuaderno de campo. Hay que destacar que previamente no habían recordado su presencia en el patio escolar, pese a que sí que los habían visto.

Una salamandra común les llamó mucho la atención, por su tamaño, movimiento y coloración, siendo incluida en todos los cuadernos de campo. Pese a ser una especie relativamente frecuente en la ciudad, con una historia natural muy llamativa y altamente simbólica (Chachero y Álvarez 2016), no conocían su presencia ni en el patio escolar ni en la ciudad. A partir de ella se elaboraron relaciones entre la coloración de advertencia (aposemática) en la naturaleza (negra y amarilla en este caso) y en algunas de las señales que empleamos para avisar de peligros (si bien en el caso de la salamandra no es peligrosa para las personas, lo que también quedó claro en el aula). Hay que tener en cuenta que el empleo de esta especie emblemática han conseguido una mayor conexión afectiva con la naturaleza en otros contextos educativos (Barthel et al. 2018), y en nuestro caso su localización representó un incremento de salidas sucesivas al patio escolar buscando más animales que les habían pasado desapercibidos.

El empleo esporádico de unos prismáticos permitió que el alumnado se familiarizara con esta herramienta, y facilitó la observación de animales presentes fuera del patio (como una vaca en los campos próximos). En el caso de las aves, se remarcaron las características diagnósticas más claras. Si bien la diversidad no fue muy amplia (gorrión común, gaviota patiamarilla, palomas bravía y torcaz, urraca), permitió que aprendieran sus diferencias y reforzar su interés en la actividad al poder identificarlas.
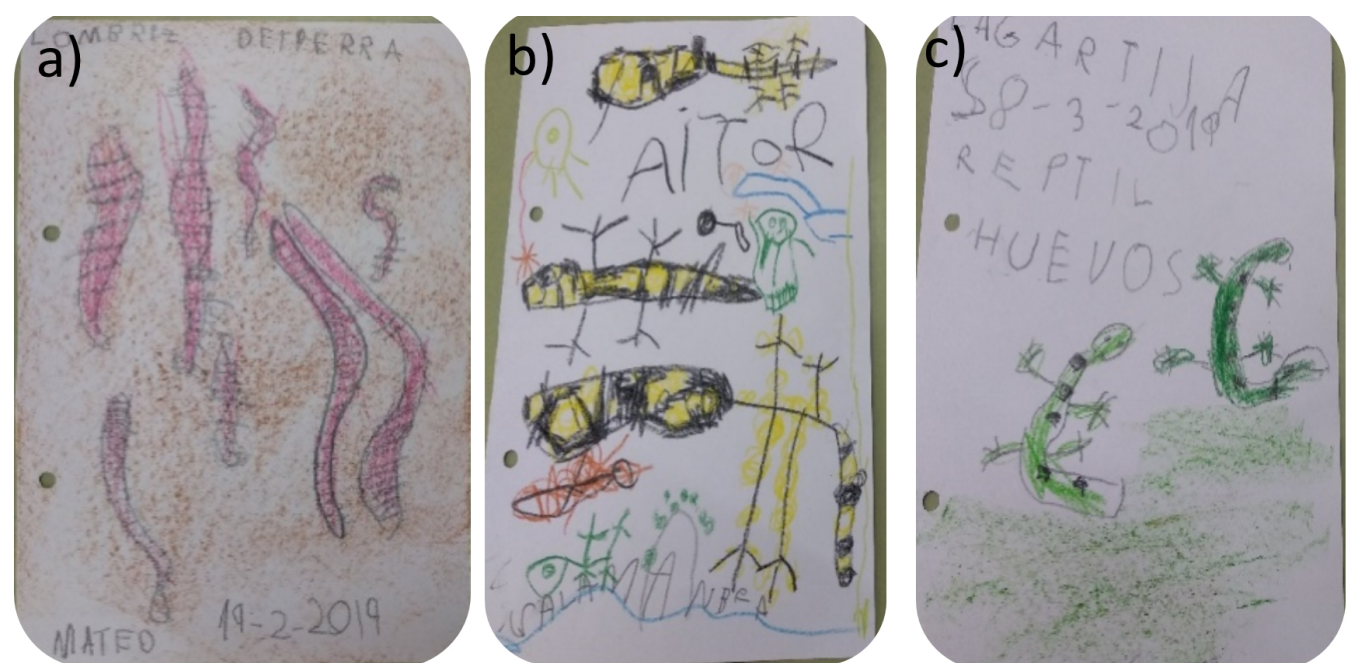

Figura 3. Recogida de información sobre animales encontrados en el patio escolar: a) lombriz de tierra, con dibujo en el que se observa su cuerpo alargado y anillado, identificación y fecha -el reverso de la hoja contenía las palabras clave anillos y compost-; b) apuntes gráficos sobre la salamandra, con su coloración aposemática; c) apuntes gráficos sobre las lagartijas, incluyen fecha de observación, grupo taxonómico y anotación sobre su historia natural. 


\section{Experiencias incorporando el huerto escolar}

El desarrollo de la clásica actividad de germinación de semillas, introduciendo algunas variables, permitió avanzar en su comprensión de la germinación y del empleo del material y lugares más apropiados para llevar a cabo la experiencia. Al poder elegir la herramienta (botella con pulverizador, un gotero y una jeringuilla) con la que "regar" (humedecer) las semillas colocadas en los algodones, optaron por realizar algunas pruebas. Así, manipularon previamente las herramientas, valoraron su comodidad al usarlas, según grado de motricidad y uniformidad con la que quedaba mojado el algodón. Aunque en algún caso la jeringuilla acaparara más interés inicial, acabaron eligiendo la botella con el pulverizador atendiendo al resultado de las pruebas realizadas.

Respecto al lugar en el que colocar los tarros con las semillas para su desarrollo, deciden como grupo situarlos cerca de la ventana del baño, con fácil acceso, por estar así cerca del agua para regarlas y para que puedan recibir la luz solar. Es interesante señalar que esta cuestión de la luz surge al realizar la reflexión conjunta sobre dónde colocar los tarros, ya que no aparecía en la identificación de ideas previas de la asamblea. Y también que, una vez considerada, es incluida por el alumnado en el dibujo realizado en el cuaderno de campo individual en todos los casos, remarcando así la decisión a la que han llegado sobre el desarrollo de las plantas. En el cuaderno también incluyen dibujos de los materiales empleados (bien de todos, bien solo del empleado finalmente) y anotan la especie y la fecha de inicio del experimento.

Tras la reflexión sobre el efecto de la luz en el desarrollo de la planta, surge la duda de si las plantas pueden germinar y sobrevivir sin luz, por lo que se les propuso un experimento al respecto, controlando la variable luz/no luz sobre los tarros anteriores mediante una caja de cartón. El alumnado debía realizar hipótesis sobre lo que iba a pasar. Las más apoyadas fueron que no germinaría la semilla dentro de la caja, que pasaría algo de luz por la caja, o que el no se podría regar el tarro al estar dentro de la caja. El alumnado fue realizando anotaciones gráficas comparando ambos casos conforme pasaban los días, y comprobaron con asombro que la planta privada de luz crecía de hecho más rápido y alto que la que sí recibió luz, si bien con distinta coloración y más delgada, doblándose finalmente. Además de introducir al alumnado en el método científico y la experimentación, la actividad permitió aprender sobre el papel de la luz en el crecimiento y la alimentación de las plantas, y hablar sobre las reservas almacenadas en las semillas. El resultado de que crecieran las plantas sin luz aunque fuera de forma distinta, ajeno a las hipótesis que habían realizado, consiguió motivar al alumnado, que expresó su deseo de realizar más experimentos sobre las plantas. Dicha motivación permitió la inclusión de la experiencia clásica de tinción de los pétalos de una flor tras echar colorante en el agua y, en este punto, el alumnado ya había interiorizado el proceso de registrar el desarrollo de los experimentos en el cuaderno (Figura 4).

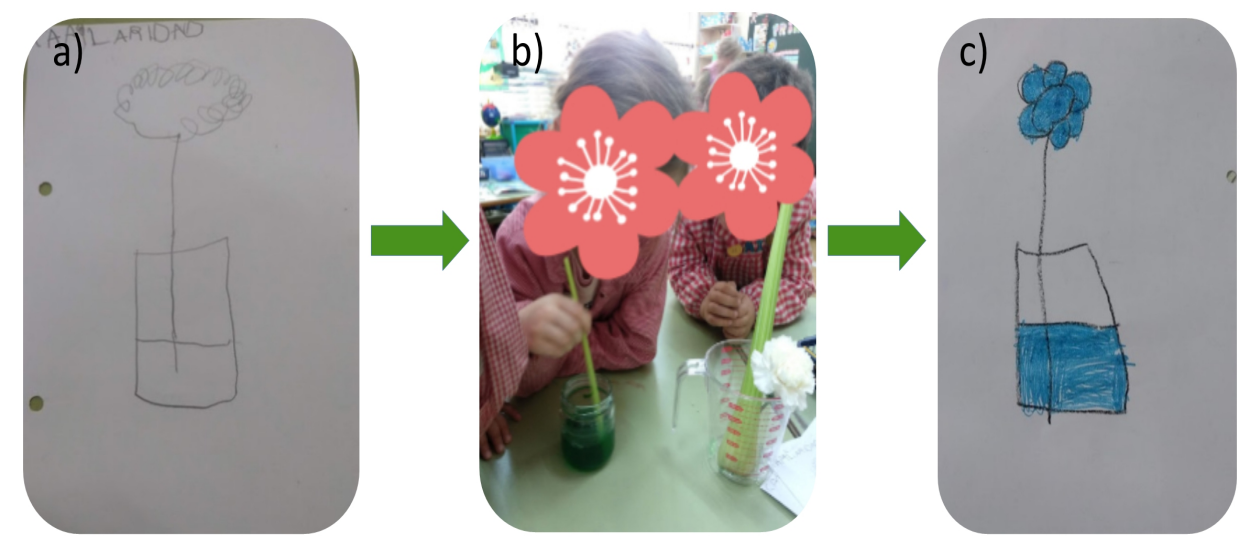

Figura 4. Experimento sobre capilaridad y transporte de sustancias por el agua: a) apunte gráfico descriptivo inicial; b) estudiantes realizando el experimento; c) apunte gráfico descriptivo final. 
Otras experiencias que incorporaron el huerto escolar permitieron (1) avanzar en la observación y tiempos del crecimiento de las plantas, (2) trabajar con otras características identificativas de las plantas como su olor, (3) aprender sobre usos plantas en el sector del huerto aromático, y (4) sobre la reducción de residuos y el reciclaje de la materia orgánica. Como efecto colateral de esta última actividad, al incorporar la rutina de compostaje se observaron cambios en la alimentación del alumnado en el aula, que trajo más fruta para para el almuerzo de media mañana que antes de comenzar con la experiencia. Esto es, la realización de la actividad consiguió modificar de forma positiva comportamiento y alimentación del alumnado hacia una más saludable y medioambientalmente más sostenible.

La integración de los elementos naturales vegetales (semillas) en los experimentos realizados en el aula ha permitido la reflexión y el planteamiento de hipótesis sobre algunas cuestiones que previamente no se había planteado el alumnado. En algunos casos, se trata de cuestiones empleadas en el aprendizaje de características físicas (como el estudio de su flotabilidad), mientras que en otros se mostraba la relación entre estas características físicas y rasgos biológicos de esas plantas (anemocoria o dispersión de las semillas por el aire), dando una visión más global al aprendizaje. Resulta interesante destacar que, en ambos casos, las hipótesis más frecuentes del alumnado relacionaban el tamaño como la característica que definiría su flotabilidad, o el tiempo de permanencia en el aire (relación inversa que se manifestaba en considerar que el guisante iba a tardar más en caer que el haba). No obstante, cabe señalar que una alumna planteó la hipótesis de que la sámara de arce sí que volaría, apoyándose en que tenía forma de alas. La información sobre el experimento (hipótesis previa y resultados obtenidos) fue recogida en el cuaderno de campo a través de páginas preformateadas en las que tenían que rellenar huecos (Figura 8 en el Anexo 1), lo que facilitó la comparación visual posterior y remarcó la importancia de los registros estandarizados de datos a la hora de realizar ciencia.

\section{Consideraciones finales}

La experiencia didáctica desarrollada en el patio vegetado y usando el cuaderno de campo como eje del aprendizaje ha representando cambios importantes desde la situación inicial (Figura 5). El potencial didáctico del patio escolar, con tierra y vegetado, se encontraba subutilizado en lo que respecta al conocimiento del entorno natural desde una perspectiva científica en Educación Infantil. Con el desarrollo de esta experiencia se ha configurado como una inmensa fuente de recursos didácticos para el aprendizaje de la naturaleza cercana. En el patio escolar de un colegio urbano se puede aprender, desde la Educación Infantil y adaptado a esta etapa, conocimientos de las ciencias experimentales, especialmente pero no solo los relacionados con la Biología (Botánica, Zoología, Ecología), sino también con Física y, fuera de las experimentales, con Matemáticas, como habían mostrado experiencias en patios más naturalizados (Equipo de Educación Infantil del C.P. Marcos del Torniello, 2020). Se ha establecido como costumbre la observación naturalística, preparado al alumnado para la identificación de árboles mediante la clasificación de hojas, y la comprensión de las partes de las plantas.

El empleo del cuaderno de campo, para registrar las observaciones naturalísticas y los resultados de los experimentos realizados ha aumentado la motivación para el aprendizaje de la lectoescritura y la animación a la lectura, lo que resulta coherente con estudios realizados en otras disciplinas (Erickson y Wharton-McDonald 2019). Es fundamental tener en cuenta que, en este proceso de aprendizaje tan difícil, la madurez y la motivación del alumnado puede resultar determinante. En esta experiencia hemos podido comprobar como cuando llega el momento de realizar ejercicios de escritura en el aula, en lo que podríamos denominar fichas clásicas, hay estudiantes que muestran menor disposición/interés que al otorgar una finalidad real a este ejercicio de escritura, realizando anotaciones sobre hipótesis, observaciones realizadas, toma de datos o su análisis. Esto es, se ha empleado como un cuaderno de campo clásico, a la vez que 
como cuaderno de laboratorio para los experimentos, facilitando la reflexión y registro del procedimiento científico, importante también para trabajar el discurso y metodologías científicas en esta etapa (Aragón, Sánchez y Enríquez 2021; Cantó y Serrano 2017). El acto reflexivo a la hora de realizar apuntes gráficos (dibujos) y escritos (palabras claves y fechas) ha contribuido a un mayor conocimiento de la biodiversidad urbana. Al inicio, el alumnado apenas se había fijado en unas pocas especies de animales y plantas del patio escolar, mientras que ha terminado la experiencia conociendo bastantes de los árboles y arbustos, además de haber incrementado notablemente el número de animales y de observaciones sobre su historia natural. La potencialidad del uso del cuaderno de campo en el aprendizaje de la ciencia se ve favorecido por la capacidad del dibujo para desarrollar las representaciones mentales del alumnado (comprobado igualmente en otras etapas educativas: Gómez Llombart y Gavidia Catalán 2015), y afianzar así los conocimientos científicos observados (Katz 2017).

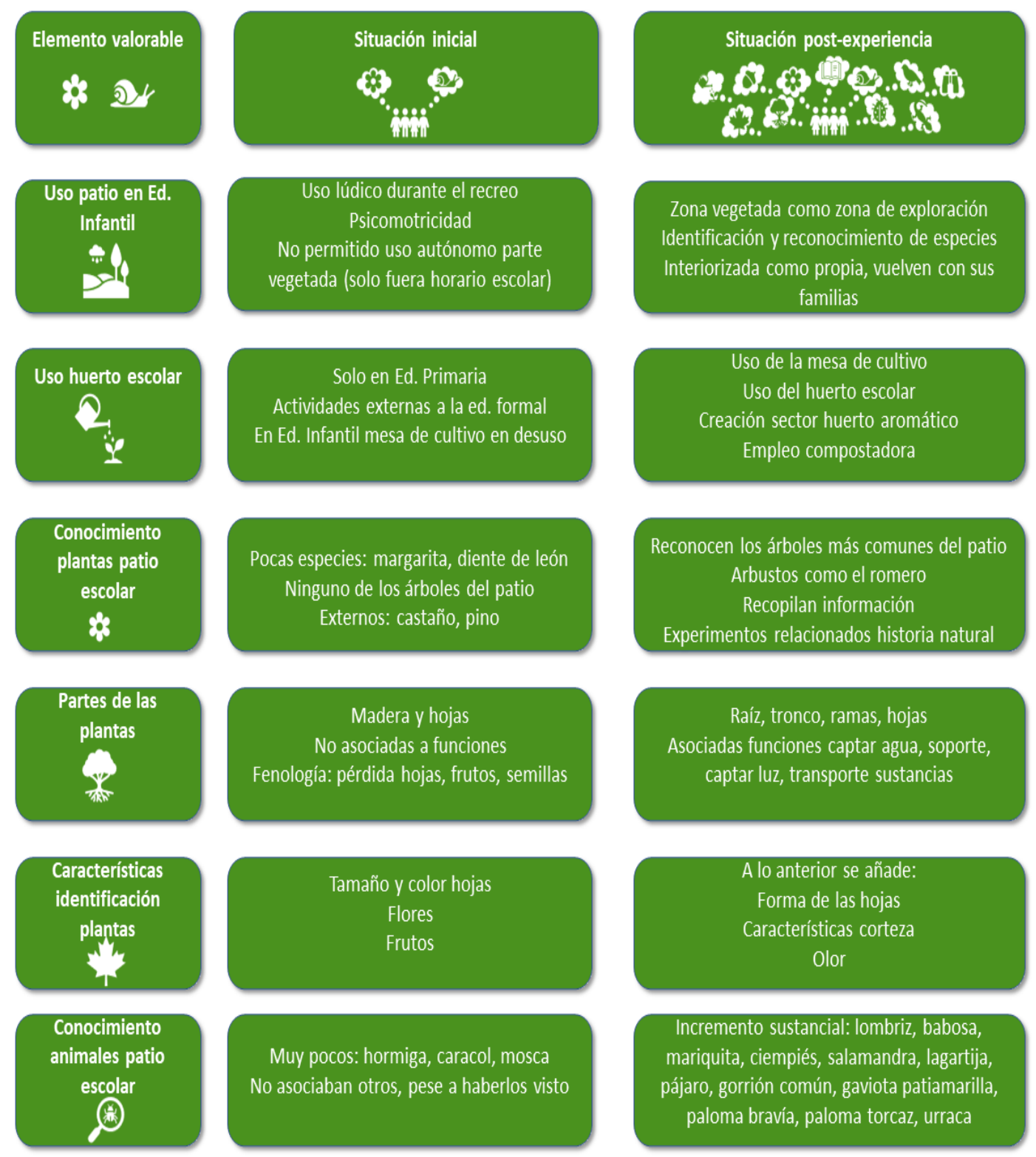

Figura 5. Cambios observados en el uso del patio escolar y el conocimiento sobre la naturaleza cercana del alumnado tras la realización de la experiencia didáctica. 
Con esta propuesta de actividades se ha intentado que el alumnado desarrolle una implicación real y activa en el cuidado del medio ambiente, incorporando al aula algunas rutinas que ofrecen una forma de comprender algunos procesos biológicos, como el compost, hablando del reciclaje de residuos orgánicos. De esta forma podemos ver como esta motivación ha conducido a una mejora de la alimentación en el aula.

Se ha incrementado el uso de la biblioteca escolar (en cuanto a la mayor frecuencia con la que acudía el alumnado a consultar libros con la motivación directa de la experiencia), potenciando la alfabetización en medios (libros y nuevas tecnologías) de forma autónoma, y también la animación a la lectura, ofreciendo al alumnado publicaciones para su edad, pero también destinadas al público adulto, que en una primera instancia generan mayor curiosidad, al tratarse de libros para mayores. En ese sentido, la utilización de libros de consulta/guías con información sobre la naturaleza, cuya edad recomendada dista considerablemente de la del alumnado, ha resultado muy positiva. Conocer y manejar libros de diferentes tipologías y formatos (libro-juego, álbum ilustrado, enciclopedias...) sumado a la motivación extra que supone emplear libros para mayores, les motiva e incita a la lectura y búsqueda en las ilustraciones.

La utilización del patio vegetado como lugar de aprendizaje y fuente de recursos sobre el medio natural, así como el empleo del cuaderno de campo como eje de ese aprendizaje, se ha mostrado adecuada para el último curso del segundo ciclo de educación infantil, consiguiendo tanto el aprendizaje como la motivación del alumnado.

\section{Agradecimiento}

El personal docente del centro, se ha interesado por las actuaciones que realizamos, invitándonos a compartir con su alumnado nuestras experiencias y aprendizajes, y ofreciendo materiales y ayuda. Las familias del alumnado se han implicado en la experiencia, aportando al aula materiales recogidos durante sus salidas al parque y poniendo en práctica algunas propuestas de observación activa de la naturaleza cercana. Debemos un especial agradecimiento al apoyo prestado por $\mathrm{M}^{\mathrm{a}}$ del Pilar Sánchez Botrán, tutora en la etapa, así como por el conserje del centro, Bernardino Gutiérrez Meré, quien ha proporcionado muchas curiosidades sobre los árboles del patio escolar.

\section{Referencias}

Abelleira Bardanca A. (2016) Educar en la naturaleza en el asfalto. RELAdEI. Revista Latinoamericana de Educación Infantil 5.1, 106-116.

Aragón L., Sánchez S., Enríquez J. M. (2021) El discurso científico en la etapa de infantil en el contexto del huerto ecológico escolar. Revista Eureka sobre Enseñanza y Divulgación de las Ciencias 18 1103. https://doi.org/10.25267/Rev_Eureka_ensen_divulg_cienc.2021.v18.11.1103

Ballouard J. M., Brischoux F., Bonnet X. (2011) Children prioritize virtual exotic biodiversity over local biodiversity. PloS ONE 6 (8), e23152. https://doi.org/10.1371/journal.pone.0023152

Barthel S., Belton S., Raymond C. M., Giusti M. (2018) Fostering children's connection to nature through authentic situations: the case of saving salamanders at school. Frontiers in Psychology 9, 928. https://doi.org/10.3389/fpsyg.2018.00928

Baumann A., Pinto D. (2017). Mi pequeño buerto. Madrid: Susaeta.

Bögeholz S. (2006) Nature experience and its importance for environmental knowledge, values and action: recent German empirical contributions. Environmental Education Research 12 (1), 65-84. https://doi.org/10.1080/13504620500526529 
Braund M., Reiss M. (2004) Learning Science Outside the Classroom. Londres, New York: Routledge Falmer.

Brody M. (2005) Learning in nature. Environmental Education Research 11 (5), 603-621. https://doi.org/10.1080/13504620500169809

Canfield M. R. (Ed.) (2011) Field notes on science \& nature. Cambridge: Harvard University Press.

Cantó J., Serrano N. (2018) ¿Cuáles son los principales problemas para hacer presentes las ciencias en las aulas de educación infantil?: La visión de los maestros en ejercicio. Enseñanza de las Ciencias No Extraordinario, 1995-2000.

Cantó Doménech J., de Pro Bueno A., Solbes J. (2016) ¿Qué ciencias se enseñan y cómo se hace en las aulas de educación infantil? La visión de los maestros en formación inicial. Enseñanza de las Ciencias 34 (3), 25-50. http://dx.doi.org/10.5565/rev/ensciencias.1870

Chachero J., Álvarez D. (2016) Los últimos dragones de Oviedo. [DVD]. España: Documentazul.

Conde Campos O., Pinzolas Torremocha J. A. (2006) Los patios de recreo: espacios para la biodiversidad. Een López Martín F., de la Osa Tomás, J (Eds.), La Educación Ambiental en Aragón en los albores del siglo XXI (pp 94-96). Zaragoza: Departamento de Medio Ambiente, Gobierno de Aragón.

Cruz-Guzmán Alcalá M., García-Carmona A., Criado García-Legaz A. M. (2017) Aprendiendo sobre los cambios de estado en educación infantil mediante secuencias de preguntapredicción-comprobación experimental. Enseñanza de las Ciencias 35 (3), 175-193. https://doi.org/10.5565/rev/ensciencias.2336

Cutter-Mackenzie A., Edwards S., Moore D., Boyd W. (2014) Young children's play and environmental education in early childhood education. Springer Science \& Business Media.

Dai A. (2017) Learning form children`s drawings on nature. Pp 73-86 en Katz P. (ed.), Drawing for Science Education. An international perspective. Rotterdam: Sense Publishers.

De Alba Villaseñor V., Ramos de Robles S. L. (2020) Modelización científica escolar para explorar el sistema circulatorio en Educación Infantil. Enseñanza de las Ciencias 38 (1), 105-125. https://doi.org/10.5565/rev/ensciencias.2765

Equipo de Educación Infantil del C. P. Marcos del Torniello (2020) Escuela 3-6. Nuestro pequeño bosque 25 años creciendo. Infancia 180 (2).

Erickson J. D., Wharton-McDonald R. (2019) Fostering autonomous motivation and early literacy skills. The Reading Teacher 72 (4), 475-483. https:/ / doi.org/10.1002/trtr.1750

García-González E., Schenetti M. (2019) Las escuelas al aire libre como contexto para el aprendizaje de las ciencias en infantil. El caso de la Scuola nel BoscoVilla Ghigi. Revista Eureka sobre Enseñanza y Divulgación de las Ciencias 16 (2): 2204. https://doi.org/10.25267/Rev_Eureka_ensen_divulg_cienc.2019.v16.i2.2204

Genovart M., Tavecchia G., Enseñat J. J., Laiolo P. (2013) Holding up a mirror to the society: Children recognize exotic species much more than local ones. Biological Conservation 159, 484-489. http://dx.doi.org/10.1016/j.biocon.2012.10.028

Gómez Llombart V., Gavidia Catalán V. (2015) Describir y dibujar en ciencias. La importancia del dibujo en las representaciones mentales del alumnado. Revista Eureka sobre Enseñanza y Divulgación de las Ciencias 12 (3), 441-455. http://dx.doi.org/10.25267/Rev_Eureka_ensen_divulg_cienc.2015.v12.i3.04 
Gómez-Motilla C., Ruiz-Gallardo J.-R. (2016) El rincón de la ciencia y la actitud hacia las ciencias en educación infantil. Revista Eureka sobre Enseñanza y Divulgación de las Ciencias 13 (3), 643-666. https:// revistas.uca.es/index.php/eureka/article/view/2996

Hayes M. A. (2009) Into the field: naturalistic education and the future of conservation. Conservation Biology 23 (5), 1075-1079. https://doi.org/10.1111/j.15231739.2009.01302.x

Heinecke L.L. (2016) Outdoor science lab for kids. Massachussets: Quarto Publishing Group USA Inc.

Jiménez Artacho C., Fernández Pérez J., Fonfría Díaz J. (2004) Iniciadores en España de la enseñanza ambiental de las Ciencias Naturales. En L. Español, J. J. Escribano, M. A. Martínez (Coord.), VIII Congreso SEHCYT: Historia de las ciencias y de las técnicas (pp. 537555). Logroño. Universidad de la Rioja.

Katz P. (2017) Drawing for Science Education. An International Perspective. Rotterdam: Sense Publishers.

Kneidel S (1993) Creepy Crawlies and the Scientific Method: more than 100 hands-on science experiments for children. Colorado: Fulcrum Publishing.

López Martínez J. D., Delgado Martínez M.Á. (2014) La enseñanza de las ciencias escolares en la Revista de Pedagogía (1922-1936). Educació i Història: Revista d'Història de l'Educació 24, 69-101. https://doi.org/10.2436/20.3009.01.135

Louv R. (2018) Los últimos niños en el bosque. Madrid: Capitán Swing.

Loxley P. (2018) Practical Ideas for Teaching Primary Science. Inspiring Learning and Enjoyment. Londres: Routledge.

Marín I., Molis C., Martínez M., Hierro E., Aragay X. (2010) Els patis de les escoles: espais d'oportunitats educatives. Barcelona: Fundació Jaume Bofill.

Mérida Serrano R., Torres-Porras J., Alcántara Manzanares J. (eds.) (2017) Didáctica de las ciencias experimentales en educación infantil. Un enfoque práctico. Madrid: Editorial Síntesis.

Monteira S. F., Jiménez Aleixandre M.P. (2019) ¿Cómo llega el agua a las nubes? Construcción de explicaciones sobre cambios de estado en educación infantil. Revista Eureka sobre Enseñanza y Divulgación de las Ciencias 16 (2), 2101. https://doi.org/10.25267/Rev_Eureka_ensen_divulg_cienc.2019.v16.i2.2101

Pyle R. M. (2003) Nature matrix: reconnecting people and nature. Oryx 37 (2), 206-214.

Ripple W. J., Wolf C., Newsome T. M., Galetti M., Alamgir M., Crist E., Mahmoud M.I., Laurance W.F., 15,364 scientist signatories from 184 countries (2017) World scientists' warning to humanity: a second notice. BioScience 67 (12), 1026-1028. https://doi.org/10.1093/biosci/bix125

Scott G. W., Boyd M. (2016) Getting more from getting out: increasing achievement in literacy and science through ecological fieldwork. Education 3-13 44 (6), 661-670. https://doi.org/10.1080/03004279.2014.996242

Sensat Vila R. (1921) La Naturaleza en las ciudades y en la escuela. Jardines y campos de juego para los niños. Escuelas de Bosque. En Libro del Congreso Nacional de Educación convocado para 1920, (pp. 73-74). Palma de Mallorca: Establecimiento tipográfico de Francisco Soler Prats. 
Segura A. M., Torralba-Burrial A. (2019) Conceptos e infraestructuras didácticas en los procesos de enseñanza-aprendizaje de la biodiversidad en Educación Infantil: análisis de la situación en Asturias. Universitas Tarraconensis. Revista de Ciències de l'Educació 2019.2, 43-60. https://doi.org/10.17345/ute.2019.2.2653

Snaddon J. L., Turner E. C., Foster W. A. (2008) Children's Perceptions of Rainforest Biodiversity: Which Animals Have the Lion's Share of Environmental Awareness? PLOS ONE 3 (7): e2579. https://doi.org/10.1371/journal.pone.0002579

Thomer A., Vaidya G., Guralnick R., Bloom D., Russell L. (2012) From documents to datasets: A MediaWiki-based method of annotating and extracting species observations in century-old field notebooks. ZooKeys 209, 235-253. https://doi.org/10.3897/zookeys.209.3247

Torralba-Burrial A. (2019) Experiencia de aprendizaje no-formal para alumnado de Educación Primaria y Secundaria sobre libélulas (Insecta: Odonata) en el marco de la Semana de la Ciencia. Boletín de la Sociedad Entomológica Aragonesa 65, 227-230.

Torres-Porras J., Alcántara J., Arrebola J.C., Rubio S.J., Mora M. (2017) Trabajando el acercamiento a la naturaleza de los niños y niñas en el Grado de Educación Infantil. Crucial en la sociedad actual. Revista Eureka sobre Enseñanza y Divulgación de las Ciencias 14(1), 258-270.

Varela-Losada M., Vega-Marcote P., Pérez-Rodríguez U., Álvarez-Lires M. (2016) Going to action? A literature review on educational proposals in formal Environmental Education. Environmental Education Research 22 (3), 390-421. https://doi.org/10.1080/13504622.2015.1101751

Vilches A., Macías O., Gil Pérez D. (2009) Década de la Educación para la Sostenibilidad. Temas de acción clave. Madrid: Centro de Altos Estudios Universitarios de la OEI.

Villarroel J. D., Antón A., Zuazagoitia D., Nuño T. (2018) Young children’s understanding of plant life: a study exploring rural-urban differences in their drawings. Journal of Biological Education 52 (3), 331-341. https:// doi.org/10.1080/00219266.2017.1385505

Wolf L.-A., Skarstein, T. H. (2020) Species learning and biodiversity in early childhood teacher education. Sustainability 12, 3698. https://doi.org/10.3390/su1209369 
Anexo 1. Descripción actividades

\section{Aprendemos sobre las plantas}

Descubrimos las partes de las plantas

Se planteó una búsqueda del tesoro con subgrupos de 2-3 estudiantes con una plantilla con imágenes de diferentes elementos (hoja de roble, hoja de plátano de sombra, tronco y fruto del magnolio de hoja perenne) que deberían encontrar en el patio escolar. Se trató de una actividad motivacional de identificación indirecta de partes de las plantas y de alguna de las especies presentes.

El alumnado también recolectó ramas, hojas de boj y de romero, filoides de musgos... que fueron empleados en una actividad sensorial con la mesa de luz (Figura 6). Manejaron dichos elementos naturales, aprendiendo sobre transparencia, así como formas y bordes de las hojas.

Para fijarse en las características de las cortezas se realizó otra actividad sensorial, comparando tacto y vista (Figura 5). Con los ojos tapados tocaron las cortezas de diferentes especies, realizando una breve descripción oral de sus características (lisa, rugosa...) y trataron de identificarla. Se calcó con ceras la corteza sobre un folio, anotando su especie y comentando las diferencias entre los dibujos creados.

Se les presentaron en varias sesiones en tarjetas y puzles las partes de los árboles. En el patio se trabajaron en árboles reales y se realizó un mural con papel continuo perfilando la sombra de un árbol (con espacio para dibujar raíces), y se escribieron de forma cooperativa sus partes.

Identificamos las especies del patio

Se buscaron diferencias en forma, borde, tamaño y color de las hojas recogidas, con ayuda de una serie de tarjetas con imágenes simplificadas. Tras describir oralmente la hoja, el alumnado la intentaba identificar ayudándose de imágenes en libros sobre árboles (Figura 2), perfilándola en su cuaderno de campo y anotando forma y especie.
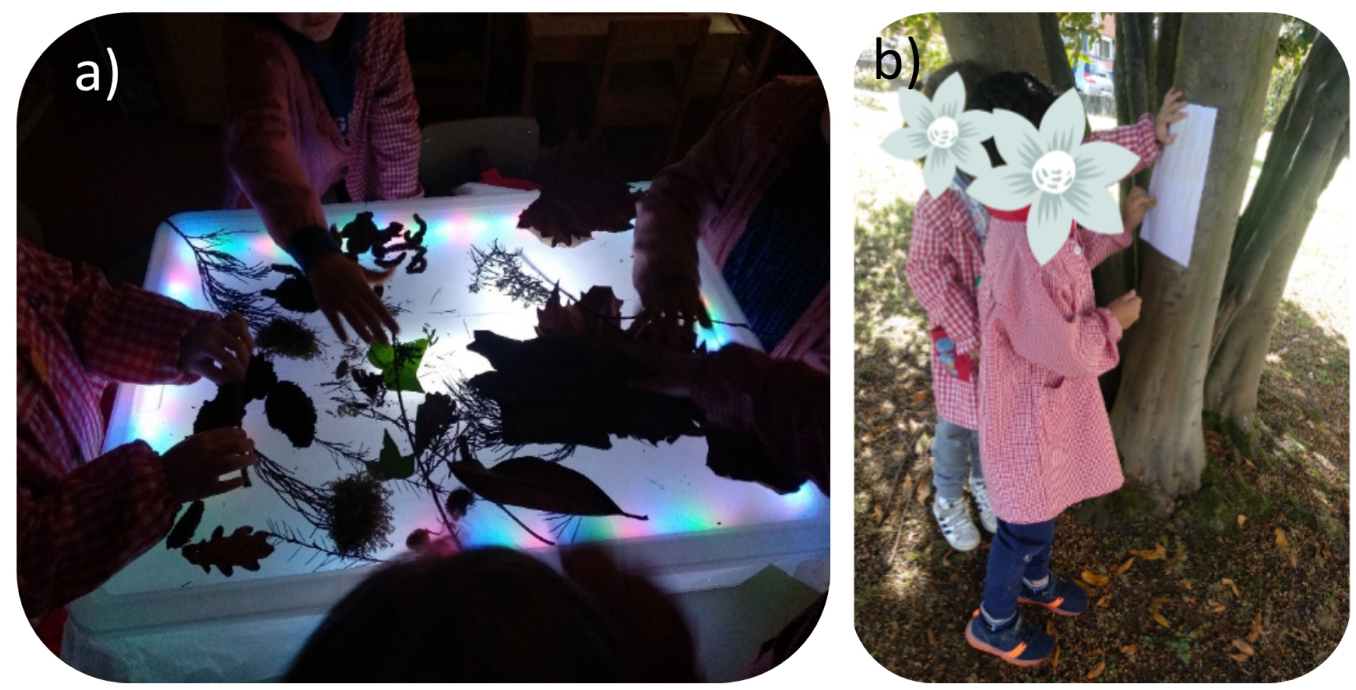

Figura 6. Experiencias sensoriales para aprender sobre algunas características de las plantas: a) explorando transparencias y formas hojas con la mesa de luz; b) explorando con el tacto y extrayendo calcos de las cortezas.

Se realizaron carteles para cada especie con un código QR que mostrara características significativas seleccionadas por el alumnado, colocándolos en el patio y añadiendo esa información en el cuaderno de campo conjunto. 


\section{Experimentamos sobre el desarrollo de las plantas}

Partiendo de la habitual actividad de germinación, se introdujeron variables. Con semillas de garbanzo y alubias, se exploraron manipulativamente las herramientas para el riego. Registraron en el cuaderno de campo un pequeño esquema del experimento, materiales, situación y anotaron semilla empleada y fecha de siembra. En las siguientes semanas, el alumnado rellenó gráficamente los cambios observados en su planta.

Se realizó un experimento siguiendo el método científico para valorar la necesidad de luz en la germinación e inicio desarrollo plantas. Así, se sembraron semillas (lentejas) en envases plásticos iguales, proporcionándoles mismas condiciones de riego, pero dejando unas con luz natural y otras a oscuras dentro de una caja de cartón.

Se enlazó con la experiencia de teñir plantas (clavel blanco, tallo de apio) añadiendo colorante líquido al agua y dibujando el desarrollo en el cuaderno (Figura 4).

\section{Continuamos con experiencias en el buerto escolar}

El grupo participó en una actividad sobre compostaje (Figura 7). Se comprobaron en asamblea conocimientos previos y sus experiencias y se visionaron dos vídeos infantiles (Peppa Pig, Sésamo). Se añadió un cubo en la zona de reciclaje del aula para estos residuos, llevándolos el encargado del día a la compostadora.

Tras leer el libro de Bauman y Pinto (2017) sobre las labores del huerto, salieron a la mesa de cultivo a realizarlas: airear la tierra, realizar pequeños hoyos con las manos y las palas, colocar brotes de lechuga, regar (Figura 7).

Se exploró la producción de plantas aromáticas, con esquejes de lavanda y tomillo, aprovechando briks usados (reducción de residuos). Se colocaron en el patio en las cercanías del romero, acompañándolas de carteles con sus nombres y Huerto aromático (Figura 7).

Se buscó información sobre el romero en Internet, usos culinarios y medicinales. En el patio se observaron su aspecto y olor. Se cortaron ramitas e hicieron varios ramilletes, secándolos para hacer unos saquitos aromáticos, y se pegó una ramita junto a su dibujo en el cuaderno.
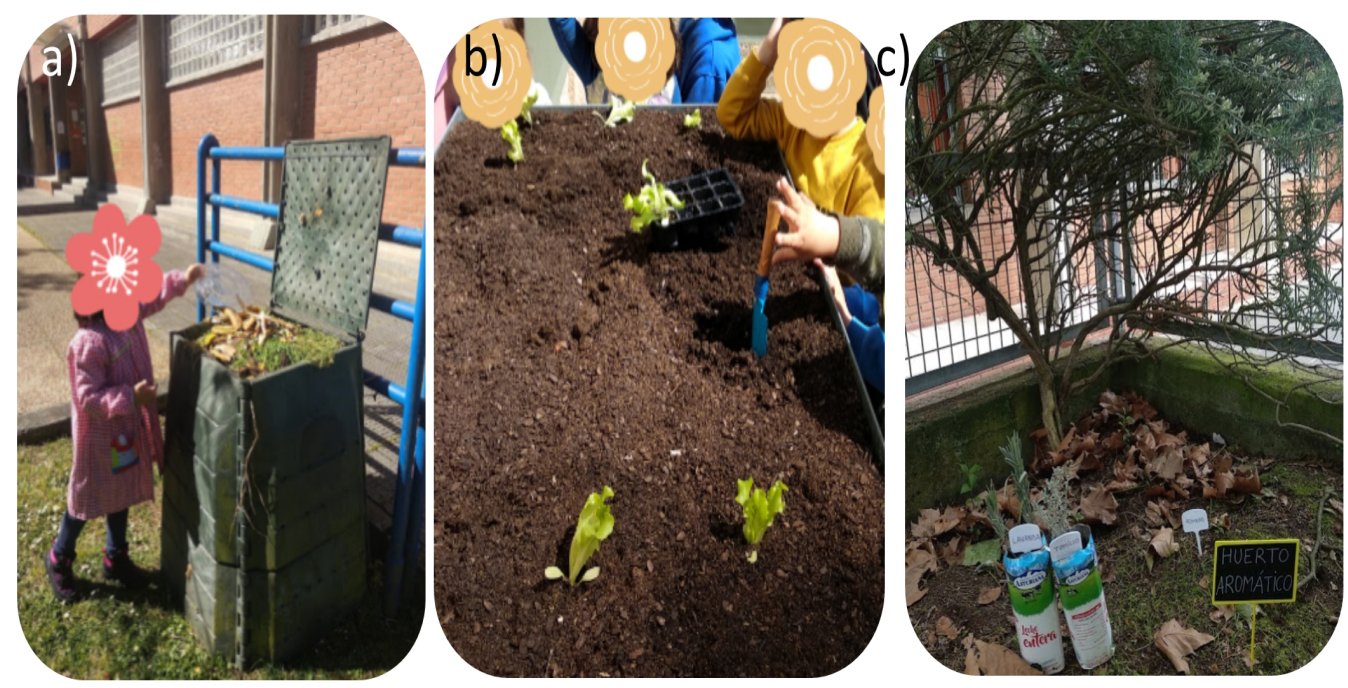

Figura 7. Algunas de las experiencias de introducción al huerto escolar: a) compostaje; b) plantación de lechugas en mesa de cultivo; c) establecimiento sector del huerto aromático. 


\section{Aprendemos sobre los animales}

Se incorporó el uso de la lupa y, en alguna ocasión, de prismáticos. Realizaron una búsqueda de imágenes e información de los animales observados en los libros del Rincón de la Naturaleza y en la tableta. Las observaciones se recogieron en el cuaderno de campo, mediante un dibujo y la elección de dos o tres palabras clave. En sesiones posteriores se indicaron las partes del cuerpo (Figura 3).

Para facilitar la observación de pequeños animales del patio escolar se colocó una trampa de caída para invertebrados edáficos. El alumnado decidió el lugar donde colocarla en la zona vegetada del patio y la enterró. Se colocó un cartel de aviso Por favor no tocar, estamos investigando que sirvió también de autoafirmación del alumnado. Realizaron dibujo de la trampa en el cuaderno de campo y la revisaron diariamente, llevando las capturas al aula para observar a través de la lupa, identificarlas y hacer una anotación en el cuaderno con la fecha, especie y dibujo. Después se liberaba al animal (una mariquita, un caracol, tres lombrices, cinco babosas y un ciempiés).

\section{Incorporamos recursos del patio a nuestro aprendizaje experimental}

Se les proporcionaron diversas semillas para que las manipularan y experimentaran sobre flotación. Observaron las diferencias entre ellas, las pesaron con una báscula y midieron con una regla como introducción a los instrumentos de medida. Realizaron hipótesis sobre qué pasaría si las echaban en un recipiente con agua, rellenaron los huecos de una hoja preformateada con esas hipótesis, hicieron el experimento y apuntaron los resultados.

Siguiendo con el aprendizaje experimental que permitiera aprender más sobre las plantas, se trabajó la posible dispersión por el aire de algunas semillas (garbanzos, guisantes, habas, sámaras de arce), experimentando al lanzarlas al aire en el patio escolar. El alumnado planteó hipótesis en una hoja preformateada, realizó el experimento y marcó lo realmente ocurrido (Figura 8).

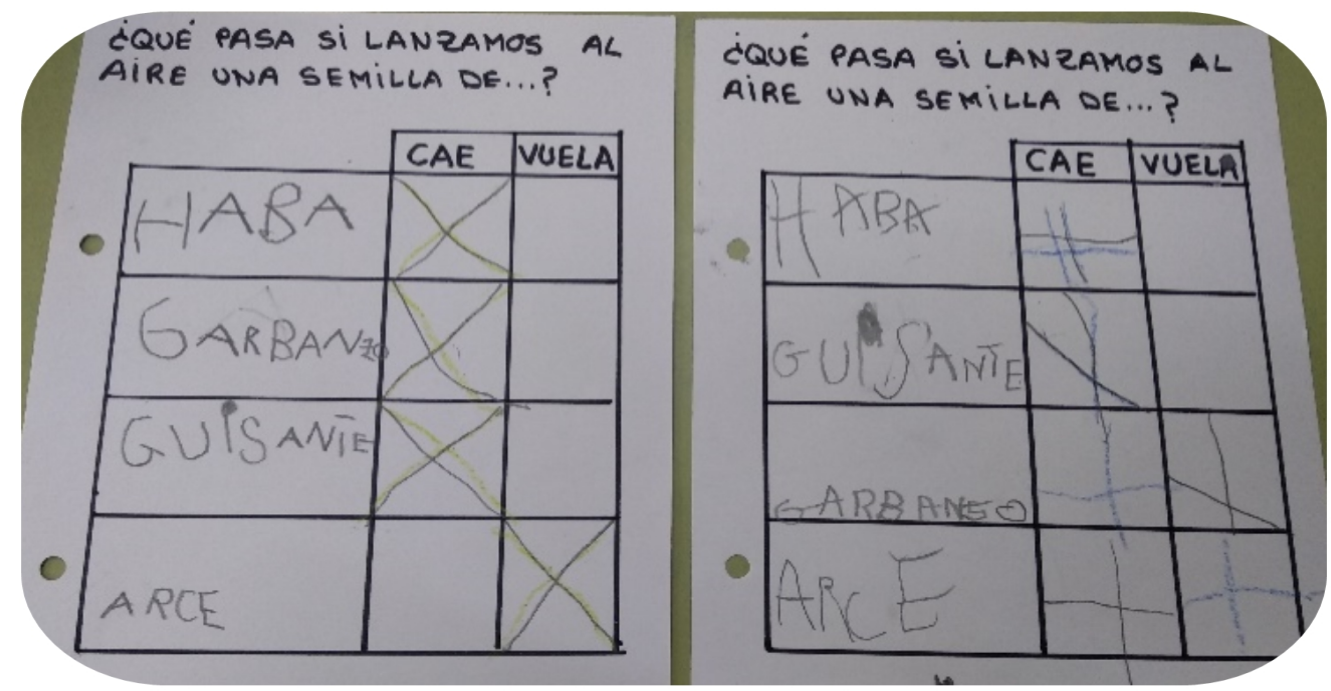

Figura 8. Ejemplo de recogida de información en el cuaderno de campo a través de páginas preformateadas: explorando la anemocoria de algunas semillas; hipótesis indicadas con lápiz, resultados con cera. 